\title{
Does the addition of losartan improve the beneficial effects of ACE inhibitors in patients with anterior myocardial infarction? A pilot study
}

\author{
P Di Pasquale, V Bucca, S Scalzo, S Cannizzaro, A Giubilato, S Paterna
}

\begin{abstract}
Objective-To verify the efficacy of the combination of captopril ( $75 \mathrm{mg}$ day) and losartan ( $25 \mathrm{mg} /$ day) in early postinfarction phases of reperfused anterior acute myocardial infarction.
\end{abstract}

Design and patients-99 patients, hospitalised for suspected anterior acute myocardial infarction within four hours from the onset of symptoms, were randomised into two groups: group A included 50 patients who received captopril $75 \mathrm{mg} /$ day and placebo; group $B$ included 49 patients who received captopril $75 \mathrm{mg} / \mathrm{day}$ within three days of admission plus losartan $12.5 \mathrm{mg}$, as a first dose, and $25 \mathrm{mg} /$ day successively. An additional 23 patients with anterior acute myocardial infarction received losartan $25 \mathrm{mg}$ alone and acted as controls (group C) to check the effects of losartan on plasma angiotensin II (AII) concentrations. Noradrenaline (norepinephrine) (NA) and AII plasma concentrations were measured on the third and 10th day after admission in 93 patients ( 35 from group A, 35 from group B, and 23 from group $($ ). 90 days after admission patients underwent echocardiography to determine end systolic volume (ESV) and ejection fraction (EF).

Results-Patients in groups $A$ and $B$ were similar with regard to age, sex, creatine kinase peak, EF, ESV, and risk factors. Group B (captopril plus losartan) patients showed a significant reduction in mean (SD) systolic blood pressure within the group (basal 128 (10) $\mathrm{mm} \mathrm{Hg;} 10$ days $\begin{array}{lll}\text { after admission } 105 & \text { (9) } \mathrm{mm} \mathrm{Hg} \text {, }\end{array}$ $\mathrm{p}<0.001$ ), and in comparison with group

Division of Cardiology, "Paolo Borsellino",GF Ingrassia Hospital, Via Val Platani 3, 90144 Palermo, Italy

P Di Pasquale

V Bucca

S Scalzo

S Cannizzaro

A Giubilato

Department of Internal Medicine, University of Palermo, Italy

S Paterna

Correspondence to: Dr Di Pasquale.

Accepted for publication 25 January 1999
$7.98(4.92) \mathrm{pg} / \mathrm{ml}$ on the 10 th day) than patients in either group $A$ or $B$ $(p=0.006)$. After 90 days following treatment, group B (captopril plus losartan) patients had a smaller ESV than patients in group A (captopril) and group C (losartan).

Conclusion-The data suggest that the combination of captopril plus losartan is feasible in the early treatment of acute myocardial infarction patients, and it appears that this combination has more effect on ESV than captopril alone in the short term.

(Heart 1999;81:606-611)

Keywords: acute myocardial infarction; angiotensin converting enzyme inhibitors; captopril; losartan

In the last few years, angiotensin converting enzyme (ACE) inhibitors have been used in early postinfarction for their known action on remodelling. ${ }^{1}$ The GISSI $-3^{2}$ and ISIS $-4^{3}$ trials have shown the feasibility of using ACE inhibitors in early phases of acute myocardial infarction (MI). Activation of the renin angiotensin system (RAS) during the acute and subacute phases of acute MI engenders an increase in circulating concentrations of noradrenaline (norepinephrine) (NA) and angiotensin II (AII). ${ }^{4}$ Unfortunately, undesirable side effects occur from therapeutic use of these nonspecific kininases. ${ }^{5}$ Losartan is a novel, orally active, non-peptide AII receptor antagonist that specifically blocks the AT 1 AII receptors. ${ }^{67}$ Early studies have shown that losartan inhibits the AII mediated pressor response in healthy subjects. ${ }^{8}$ A single dose study in patients with heart failure showed beneficial vasodilator and neurohormonal effects of losartan in these patients ${ }^{9-11}$ Recently, studies were designed to examine the safety and neurohormonal effect of losartan, when administered to patients with heart failure treated with ACE inhibitors. ${ }^{12}$ As the AII concentrations may recover during chronic treatment, perhaps by an alternate pathway (chymase), ${ }^{13}$ these rising concentrations may attenuate the haemodynamic effects of ACE inhibitors. In these patients AII receptor blockade may provide further benefit. ${ }^{14}{ }^{15}$ Recently, experimental studies compared the effect of losartan versus captopril in rats with large $\mathrm{MIs}^{16}$ and during ischaemia reperfusion. ${ }^{17} \mathrm{~A}$ recent report showed the feasibility of using an ACE inhibitor and losartan in combination in early postinfarction. ${ }^{18}$ To evaluate the efficacy (98) $\mathrm{pg} / \mathrm{ml}$; AII 5.31 (2.25) $v 6.09$ (3.31) pg/ $\mathrm{ml})$. However, patients in group $\mathrm{C}$ had higher plasma concentrations of AII (14.79 (5.7) $\mathrm{pg} / \mathrm{ml}$ on the third day and 
of captopril plus losartan, and to verify if this combination is able to avoid the increase of AII found with losartan treatment alone, ${ }^{13}{ }^{14}$ a randomised single blind study involving patients with anterior acute $\mathrm{MI}$ in the early postinfarction phase was carried out.

\section{Patients and methods}

PATIENT POPULATION AND ELIGIBILITY CRITERIA From January 1996 to February 1998, 574 patients were admitted consecutively to hospital with suspected acute MI. To be eligible to enter the trial, patients had to have a first episode of anterior acute MI, Killip class I-II, an acceptable echocardiographic window, and to be admitted to hospital and thrombolysed within 4 hours of the onset of symptoms (pain). On ECG there had to be an ST elevation of $>1$ $\mathrm{mm}$ in the peripheral leads and/or $2 \mathrm{~mm}$ in precordial leads, involving more than one lead, with concomitant alterations of the segmentary kinetics in the echocardiogram performed at entry. The basal creatine kinase (CK, CK-MB isoenzyme before thrombolysis) had to be within the normal range. All patients admitted into the study had to have successful reperfusion and had to receive the target dose of captopril $(75 \mathrm{mg} /$ day $)$ three days after admission. There was no age limit. Informed consent was obtained from all patients.

Patients were excluded from the study if they were not suitable for thrombolysis, subsequently did not satisfy the reperfusion criteria, had left bundle branch block on the admission ECG, a history of cardiomyopathy, or had heart failure. Patients receiving ACE inhibitors, $\beta$ blockers, and a captopril dose $<75 \mathrm{mg} /$ day three days after admission were also excluded from the study. In addition, patients who did not show patency of the infarct related artery in late coronary angiography (7-10 days) were excluded. Patients who showed no enzymatic alterations after thrombolysis were classified as having unstable angina, and also excluded from the study.

REPERFUSION CRITERIA

There had to be evidence of typical behaviour of the ST segment with rapid $(50 \%)$ reduction, rapid regression of pain, an enzymatic (CK) peak within 12 hours of thrombolysis, and early ventricular arrhythmias within 2 hours of the start of thrombolysis. The CK peak within 12 hours was considered mandatory, associated with one of the other reperfusion criteria.

\section{ACUTE MI CLASSIFICATION AND TREATMENT}

Acute MIs were classified as anterior according to the localisation of the alterations in segmental contractility in the echocardiogram performed at entry and according to the localisation of the alterations of the ST segment in the standard 12 lead ECG+V3R-V4R lead taken at entry before thrombolysis.

All patients received our standard treatment: nitrates, heparin, aspirin, and, where possible, three doses of intravenous metoprolol $5 \mathrm{mg}$. The thrombolytic drug used was the accelerated recombinant tissue plasminogen activator (100 mg).
STUDY PROTOCOL

Patients suitable for thrombolysis received captopril $6.25 \mathrm{mg}$ orally, as first dose, 2-4 hours after starting thrombolysis. Blood pressure (first 6 hours), heart rate, and ECG were monitored continuously, recorded on tape (first 2 hours), and then analysed to check any rhythm disturbance, focusing attention on the time of pain cessation and regression of ST segment alteration. Ventricular tachycardia and ventricular fibrillation were recorded. Blood CK concentrations were measured every 3 hours during the first 24 hours and then every 6 hours until they returned to normal, to determine the enzymatic peak (12 hours). Providing blood pressure was $>100 \mathrm{~mm} \mathrm{Hg}$, captopril doses were increased up to $25 \mathrm{mg}$ every 8 hours (first three days). All the patients had to receive, at three days after admission, $75 \mathrm{mg}$ captopril per day. Randomisation (single blind) was carried out by sequentially numbered boxes and was decided on the third day. Figure 1 shows the outcome of the study. Patients receiving captopril $25 \mathrm{mg}$ every 8 hours after three days and with blood pressure $>120 \mathrm{~mm} \mathrm{Hg}$ were randomised (single blind) into two groups, followed by echocardiography: group A (50 patients) received captopril ( $75 \mathrm{mg} /$ day) and placebo; group B (49 patients) received captopril $(75 \mathrm{mg} /$ day $)$ plus losartan $12.5 \mathrm{mg}$ as a first dose, and then after 24 hours the dose was increased up to $25 \mathrm{mg}$ / day according to the patient's blood pressure (lower limit $110 \mathrm{~mm} \mathrm{Hg}$ ). Blood pressure was controlled continuously for 6 hours after losartan administration. In addition, 23 patients received losartan only, $12.5 \mathrm{mg}$ as first dose 2-6 hours after starting thrombolysis, the dose subsequently being increased up to $25 \mathrm{mg}$ /day. This losartan only group (group C) was used as a control to monitor the effects of losartan on plasma AII concentrations. After 10 days, when the second sampling of NA and AII was performed, the dose of losartan was increased to $50 \mathrm{mg} /$ day. Before discharge, patients underwent 24 hour Holter monitoring to evaluate late ventricular arrhythmias, taking into account only those in Lown's class $>2$, as well as a symptom limiting exercise test. All patients entered into the study underwent a haemodynamic investigation (7-10 days after admission). Percutaneous transluminal coronary angioplasty (PTCA) or coronary artery bypass grafting (CABG) were performed according to angiographic findings and left ventricular function. Patients enrolled in the study continued treatment after discharge. They were regularly followed up as outpatients.

FOLLOW UP

Echocardiography was carried out according to a standard procedure on day 3 (just after randomisation) and day 90 after admission. Patients lay in the left lateral position during the examination; echocardiographic recordings were obtained at the end of the expiratory phase during normal breathing, and an apical four chamber and two chamber view was used. The end systolic volume (ESV) was measured at the end of the $T$ wave. The modified Simp- 


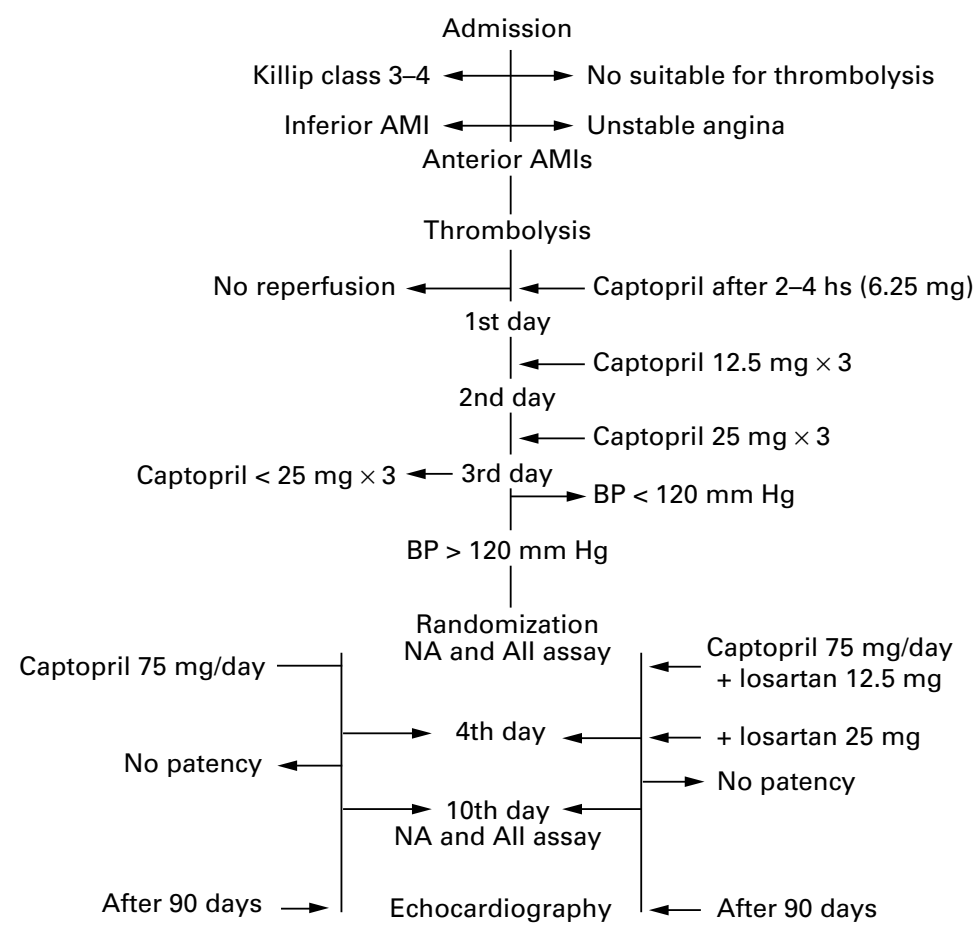

Figure 1 Study design and outcome. AMI, acute myocardial infarction; BP, blood pressure AII, angiotensin II; NA, noradrenaline.

son's rule, which uses two cross section views (four and two chamber apical views) was followed. ${ }^{19}$ All members of the study team had completed at least five years of internal cardiology residency and training in two dimensional echocardiography. Two observers blinded to the clinical and ECG data evaluated the two dimensional echocardiographic images. In case of discrepancy, the two dimensional echocardiographic images were again reviewed, and a decision was made by consensus. The mean of three measurements was used. The interobserver and intraobserver coefficients of variation were $4 \%$ and $3 \%$, respectively.

NEUROHORMONAL ASSESSMENT

Blood was obtained for measurement of NA and AII concentrations on the third day, when all the patients were given the target dose of captopril ( $75 \mathrm{mg} /$ day), and on the 10 th day after admission (seven days after losartan administration); the same sampling procedure was followed in patients treated with losartan

Table 1 Clinical data and results of patients with proved reperfused anterior acute MI

\begin{tabular}{lllll}
\hline & $\begin{array}{l}\text { Group } A \\
\text { (captopril) }\end{array}$ & $\begin{array}{l}\text { Group B } \\
\text { (captopril +losartan) }\end{array}$ & $\begin{array}{l}\text { Group } C \\
\text { (losartan) }\end{array}$ & p Value \\
\hline Number of patients & 50 & 49 & 23 & \\
Sex (female/male) & $13 / 37$ & $11 / 38$ & $7 / 16$ & NS \\
Age (years) & $63.3(13)$ & $62.6(12)$ & $63.9(14)$ & NS \\
CK peak max (iu/l) & $2165(1014)$ & $2105(988)$ & $2174(1115)$ & \\
CABG/PTCA & 21 & 22 & 10 & \\
VT & 41 & 38 & 14 & \\
Lown's class $>2$ & 7 & 6 & 2 & \\
B Blockers & 19 & 18 & 8 & \\
Hypertension & 23 & 20 & 10 & \\
Diabetes & 18 & 17 & 7 & \\
Hypercholesterolaemia & 17 & 16 & 9 & \\
Smokers & 14 & 13 & 5 & \\
\end{tabular}

CK, creatinine kinase; CABG, coronary artery bypass graft; PTCA, percutaneous transluminal coronary angioplasty; VT, ventricular tachycardia. alone. Plasma was obtained and frozen immediately. AII concentrations were determined by radioimmunoassay (reproducibility $10 \%$ ), after initial high performance liquid chromatography (HPLC) separation of AI and AIII, ${ }^{15}$ and NA concentrations were assessed by HPLC as previously reported. ${ }^{20}$ Neurohormonal assay was performed by a pharmacologist who was blinded to treatment, as were the physicians who performed the haemodynamic study to obtain ESV and ejection fraction (EF).

STATISTICAL ANALYSIS

Results are expressed as mean (SD). Data were analysed by the two tailed $t$ test to identify differences between the groups and analysis of variance (ANOVA) for repeated measures with Bonferroni correction for intragroup data. Nominal data were analysed by $\chi^{2}$ test; $\mathrm{p}<0.05$ was considered to be significant.

\section{Results}

Ninety nine patients met the entry criteria and continued the study in accordance with the study protocol. In addition 23 patients were given losartan alone. The patients who had proved reperfused anterior acute $\mathrm{MI}$ and late coronary angiography had an infarct related artery patency corresponding to the classification of reperfusion based on non-invasive diagnosis. Five patients in group B and seven patients in group A initially entered into the study did not show subsequent patency of the infarct related artery and were excluded. NA and AII levels in these patients were similar to those of patients enrolled into the study (group A-basal NA 706 (198) $\mathrm{pg} / \mathrm{ml}$, on 10th day 375 (152) pg/ml, basal AII 13.35 (6.5) pg/ml, on 10th day $6.2(3.8) \mathrm{pg} / \mathrm{ml}$; group B-basal NA 726 (212) $\mathrm{pg} / \mathrm{ml}$, on 10th day 387 (189) $\mathrm{pg} / \mathrm{ml}$, basal AII 13.45 (7.1) $\mathrm{pg} / \mathrm{ml}$, on 10th day $6.15(4.52) \mathrm{pg} / \mathrm{ml})$. In addition, they showed clinical signs of heart failure (EF $<40 \%$ ). The groups were similar in regard to age, sex, diabetes, smoking habits, hypertension, CK enzymatic peak, adjuvant therapy, $\mathrm{EF}, \mathrm{ESV}$, and incidence of CABG/PTCA. Table 1 shows the clinical data of patients with proved reperfused anterior acute MI and the results obtained from each group.

NEUROHORMONAL AND BLOOD PRESSURE DATA In 93 patients (35 from group A, 35 from group B, and 23 from group C) mean NA and AII concentrations (in those patients with proved reperfused anterior acute $\mathrm{MI}$ ) were reduced on the 10th day (table 2 ). AII values in samples drawn at later times tended to be lower in the captopril treated patients (group A) versus the captopril plus losartan treated patients (group B), even if the difference was not significant. The patients receiving losartan alone (group C) showed higher AII plasma concentrations in comparison with the other two groups, but the difference was significant only when compared with the captopril treated patients (group A) $(p=0.006)$. Patients in group B (captopril plus losartan) showed a significant reduction in systolic and diastolic blood pressure in comparison with patients in 
Table 2 Neurohormonal data

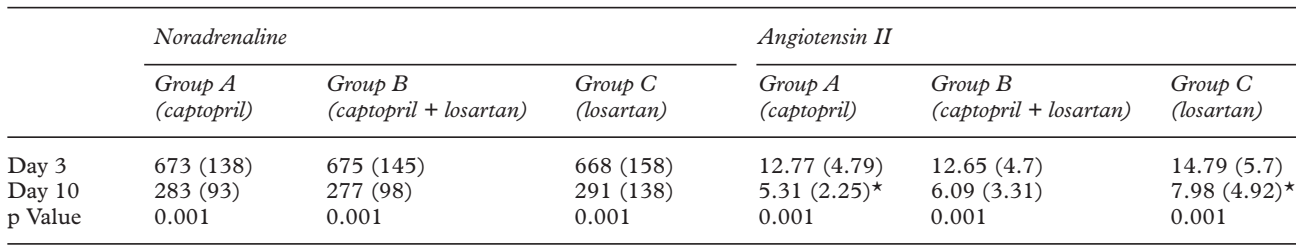

Values are mean (SD) in $\mathrm{pg} / \mathrm{ml}$.

${ }^{\star} \mathrm{p}<0.006$.

Table 3 Changes in systolic and diastolic blood pressure

\begin{tabular}{llllllll}
\hline & \multicolumn{3}{l}{ Systolic blood pressure } & & & \multicolumn{2}{l}{ Diastolic blood pressure } \\
\cline { 2 - 3 } & $\begin{array}{l}\text { Group } A \\
\text { (captopril) }\end{array}$ & $\begin{array}{l}\text { Group } B \\
\text { (captopril }+ \text { losartan) }\end{array}$ & $\begin{array}{l}\text { Group } C \\
\text { (losartan) }\end{array}$ & & $\begin{array}{l}\text { Group } A \\
\text { (captopril) }\end{array}$ & $\begin{array}{l}\text { Group } B \\
\text { (captopril }+ \text { losartan) }\end{array}$ & $\begin{array}{l}\text { Group } C \\
\text { (losartan) }\end{array}$ \\
\hline Day 3 & $127(11)$ & $128(10)$ & $131(13)$ & & $89(10)$ & $90(12)$ & $91(13)$ \\
Day 10 & $116(10)^{\star} \dagger$ & $105(9)^{\star}$ & $121(12) \dagger$ & & $77(11)^{\star \star}$ & $66(11)^{\star \star \ddagger}$ & $84(12) \ddagger$ \\
p Value & 0.001 & 0.001 & 0.001 & & 0.001 & 0.001 & 0.001 \\
\hline
\end{tabular}

Systolic blood pressure: ${ }^{\star} \mathrm{p}<0.001 ; \mathrm{tp}<0.01$.

Diastolic blood pressure: ${ }^{\star \star} \mathrm{p}<0.001 ; \neq \mathrm{p}<0.001$.

Table 4 Changes in end systolic volume and ejection fraction 90 days after treatment

\begin{tabular}{|c|c|c|c|c|c|c|}
\hline & \multicolumn{3}{|c|}{ End systolic volume $\left(\mathrm{ml} / \mathrm{m}^{2}\right)$} & \multicolumn{3}{|c|}{ Ejection fraction (\%) } \\
\hline & $\begin{array}{l}\text { Group A } \\
\text { (captopril) }\end{array}$ & $\begin{array}{l}\text { Group B } \\
\text { (captopril + losartan) }\end{array}$ & $\begin{array}{l}\text { Group } C \\
\text { (losartan) }\end{array}$ & $\begin{array}{l}\text { Group A } \\
\text { (captopril) }\end{array}$ & $\begin{array}{l}\text { Group B } \\
\text { (captopril + losartan) }\end{array}$ & $\begin{array}{l}\text { Group } C \\
\text { (losartan) }\end{array}$ \\
\hline 3 days & $46.2(14)$ & 45.9 (13) & $45.7(12)$ & $47.3(11)$ & $46.5(10)$ & $47.6(12)$ \\
\hline $7-10$ days & $45.5(9.5)$ & $43.6(10)$ & $46.8(12)$ & $47.9(8.1)$ & $49.1(6.1)$ & $47.2(10)$ \\
\hline 90 days & $48.8(9) \ddagger$ & $44.6(8) \dagger \ddagger$ & $50.3(13) \dagger$ & $48.4(9)$ & $50.8(7)^{\star}$ & $46.4(12)^{\star}$ \\
\hline $\mathrm{p}$ Value & NS & NS & NS & NS & NS & NS \\
\hline
\end{tabular}

End systolic volume $\nmid \mathrm{p}=0.023 ; \mathrm{p}=0.016$.

Ejection fraction ${ }^{\star} \mathrm{p}=0.054$.

group A (captopril) $(\mathrm{p}<0.001)$ (table 3). Group C (losartan) patients also showed a significant reduction in blood pressure by the 10 th day $(p<0.001)$. EF values were higher, though not significantly so, in group B patients (captopril plus losartan) than in group $\mathrm{A}$ patients (captopril) and group $\mathrm{C}$ patients (losartan). Serum creatinine, serum potassium, and blood urea did not show any significant differences between groups A and B. The first dose of losartan $(12.5 \mathrm{mg})$ did not produce significant changes in blood pressure.

HAEMODYNAMIC DATA

In the follow up from January 1996 to May 1998 (range 3-29 months; minimum period of observation three months from May 1998), two patients in each group died as a result of reinfarction and heart failure. Ninety five patients completed the study period of 90 days (48 from group A and 47 from group B) and underwent echocardiographic examination. The same procedure was also performed in the 23 patients in group C. ESV values at 90 days did not differ significantly from those at the start of the study in group B (captopril plus losartan) patients, but did differ slightly, though not significantly, in group A (captopril) and group C (losartan) patients (table 4). When the ESV values for the three groups at 90 days were compared, the values for group B (captopril plus losartan) differed from those for group A (captopril) $(\mathrm{p}=0.016)$ and group $\mathrm{C}$ (losartan) $(\mathrm{p}=0.023)$. There was no significant difference between the ESV values in group $\mathrm{A}$ and group $\mathrm{C}$. The $\mathrm{EF}$ values were higher in patients in group $B$ than in groups $A$ and C 90 days after admission, although the differences were not significant $(p=0.054)$ (table 4). Four ischaemic events were observed during the follow up period (one episode of reinfarction and one episode of unstable angina each in groups $\mathrm{A}$ and $\mathrm{B}$ ). In group $\mathrm{C}$ one episode of unstable angina and one of heart failure were recorded.

\section{Discussion}

Specific receptor antagonism has obvious theoretical advantages. ACE cleaves not only AI to form AII, but also cleaves bradykinin, encephalin, and substance $\mathrm{P}^{21}$ Some important side effects of ACE inhibition (cough and angioedema) are most likely caused by these non-specific actions. ${ }^{22}$ In addition, some nonconverting enzyme dependent conversion from AI to AII occurs locally within cardiac and arterial wall tissues. ${ }^{13}$ ACE inhibitor treatment appears to enhance this pathway and, thus, the blockade of the potentially detrimental effects of AII by ACE inhibitor may remain incomplete. ${ }^{14}{ }^{23}$ Blocking the actions of AII at the receptor level represents an attractive alternative approach to treatment. A favourable vasodilator and neurohumoral response in patients with heart failure has been documented for losartan. ${ }^{9-11}$ Recent reports suggest that losartan and ACE inhibitors (enalapril and captopril) are of comparable efficacy and tolerability in the short term treatment of moderate or severe congestive heart failure, whereas one long term study showed losartan reduced mortality when compared with captopril. ${ }^{11}{ }^{24}$ On the other hand, the randomised evaluation of strategies of left ventricular dysfunction 
(RESOLVD) study showed that another AII receptor antagonist, candesartan, appears to be comparable to enalapril in terms of clinical outcome. Combination treatment (enalapril plus candesartan) resulted in greater suppression of aldosterone, prevention of ventricular dilatation, and a greater reduction in natriuretic peptides. ${ }^{25}$

Thus, the question may be raised as to whether ACE is blocked sufficiently during ACE inhibitor treatment and whether this treatment could be improved..$^{9} 1024$ In fact, an additive blood pressure lowering effect was reported in hypertensive patients when an AII receptor blocker was added to an ACE inhibitor. $^{26}$ It is therefore conceivable that treatment strategies in the future may involve a two pronged approach, using both AII receptor antagonists to prevent the effects of AII on vascular and myocardial tissues, and ACE inhibitors to achieve the bradykinin/nitric oxide mediated effect. ${ }^{27} \mathrm{With}$ this scenario in mind, we considered it would be of interest to test the association between captopril and losartan in the early phases of postacute MI in a selected group of patients. Our data showed that using a combination of these drugs blocked the RAS more completely than ACE inhibition or losartan alone. ${ }^{16}$ Patients treated with captopril plus losartan (group B) showed a significant reduction in blood pressure compared with captopril alone (group A). No important side effects were observed. Furthermore, there was no significant difference in AII concentrations between the two groups seven days after treatment.

We thought that the low dose of losartan used may have caused an incomplete inhibition of AT1 receptors on the myocytes. The captopril plus losartan combination may be able to block the detrimental effects of the AII chymase dependent system with persisting concentrations of AII after ACE inhibitor treatment. It is possible that an increase in AII was not found because the conversion of AI to AII was blocked by ACE inhibition. In this way, we hoped to obtain the goal of reducing the detrimental effects of AII by losartan and probably reducing the effects of AII produced by the chymase system. The dose of losartan used was low, which perhaps lessened the major effects on the blood pressure. It would be interesting to use a lower dose of captopril and a higher dose of losartan, to determine if it is more important to block the effects of the alternative system (chymase) or the ACE system. We preferred to use enough ACE inhibitor to maintain the effects on kinins (bradykinin, prostaglandin, endothelin, etc), ${ }^{5728}$ and to determine the additive effects of losartan on AII plasma concentrations.

The reduction in AII plasma concentrations from day 3 to day 10 after acute MI in both groups is caused probably by two mechanisms: a reduction of RAS activation, observed during the acute phase of acute MI; and the effects of captopril. The lack of an increase in AII with the association of losartan was probably caused by the concomitant action of the ACE inhibitor, which did not allow an increase in
AII plasma concentrations, but to prove this hypothesis it was necessary to treat patients with losartan alone. The value of the AII concentrations measured at day 10 may be questioned in view of the short observation period. For this reason we treated a third group with losartan alone (group C), to act as a control to verify the effects of losartan on plasma AII concentrations. After 10 days, when the second sampling of NA and AII was performed, the dose of losartan was increased to $50 \mathrm{mg} /$ day. The patients receiving losartan alone (group C) showed higher AII plasma concentrations in comparison with the other two groups, but the difference was significant only when compared with the captopril group (group A) $(p=0.006)$. In addition, patients in group C (losartan) showed a significant reduction in blood pressure and no difference in ESV and EF.

It is difficult to reach a conclusion about the value of the lack of increase in AII observed in patients treated with captopril plus losartan and/or of the increase in AII observed in the patients treated with losartan alone. On the other hand, our data are in agreement with recent papers showing a significant increase of AII concentrations during short term AII receptor antagonist administration. ${ }^{8-10}$ The most striking results of this study were the safety and tolerability of the losartan plus captopril combination and the significant reduction of ESV three months after treatment. In addition, our data are in agreement with recent experimental reports showing that dual treatment with ACE inhibitors and AII receptor antagonists may provide further beneficial effects and enhance myocyte contractile performance in heart failure. ${ }^{29}$ This result must be interpreted with caution because of the selection of patients (low risk, thrombolysed, and reperfused). In the follow up, as the sample size was small, only large differences could be detected; no significant differences in the fatal and non-fatal event rates were observed between two groups. The reduction in ESV 90 days after admission could be interpreted as an effect of the captopril plus losartan combination on remodelling. These are very preliminary data which suggest further investigations are required.

LIMITS OF THE STUDY

The major limitations of the study were the small number of patients and the single blind randomisation. Because of the small number of patients we could not show possible beneficial effects on morbidity and mortality. The beneficial effects reported on early remodelling must be interpreted with caution because both groups received ACE inhibitor treatment, and were thrombolysed and reperfused. However, the patients were strictly selected in order to test, for the first time, the effects of combination treatment with losartan plus an ACE inhibitor in acute MI. For the same reason the patients were given single blind treatment.

We are indebted to Miss Valeria Anna Cuccia and Antonio Di Paola for their assistance. 
1 Pfeffer MA, Braunwald E, Moye LA, et al on behalf of the SAVE investigators. Effect of captopril on mortality and morbidity oin patients with left ventricular dysfunction after myocardial infarction: results of the survival and ven-

tricular enlargment trial. N Engl f Med 1992;327:669-77.
2 Gruppo Italiano per lo Studio della Sopravvivenza nell'Infarto Miocardico. GISSI-3: effects of lisinopril and trransdermal glyceryl trinitrate singly and together on 6-week mortality and ventricular function after acute myocardial infarction. Lancet 1994;343:1115-22.

3 Forth International Study of Infarct Survival Collaborative Group. A randomized factorial trial assessing early oral captopril, oral mononitrate and intravenous magnesium suphate in over 58050 patients with suspected acute myocardial infarction: ISIS-4. Lancet 1995;345:669-85.

4 Sigurdsson A, Held P, Swedberg K. Short and long-term neurohormonal activation following acute myocardial infarction. Am Heart f 1993; 126:1068-76.

5 Johnstone CI, Clappison BH, Anderson WP, et al. Effect of angiotensin converting converting enzyme inhibition on angiotensin converting converting enzyme inhibition on circulating $1401-4$.

6 Johnstone CI. Angiotensin receptor antagonists: focus on losartan. Lancet 1995;346:1403-7.

7 Timmermans PBMWM, Wong PC, Chiu AT, et al. Angiotensin II receptors and angiotensin II receptor antagonists. Pharmacol Rev 1993:45:205-51.

8 Goldberger MR, Tanaka W, Barchowsky A, et al. Effect of losartan on blood pressure, plasma renin activity and angiotensin II in volunteers. Hypertension 1993;21:704-13.

9 Gottlieb SS, Dickstein K, Fleck E, et al. Hemodynamic effects of the angiotensin II antagonist losartan in patients with heart failure. Circulation 1993;88:1602-9.

10 Crozier I, Ikram H, Awan N, et al for the Losartan Hemodynamic Study Group. Losartan in heart failur: hemodyMartinez FA, on behalf of ELITE Study Investigators. Randomised trial of losartan versus captopril in patients over 65 with heart failure: evaluation of losart

in the elderly study (ELITE). Lancet 1997;349:747-52.
Pitt B, Dickstein K, Benedict CR, et al for the RAAS Investigators. The randomized angiotensin receptor antagonist ACE inhibitor study (RAAS): pilot study [abstract]. Circulation 1996;94:I-428.

13 Wolny A, Clozel JP, Rein J, et al. Functional and biochemical analysis of angiotensin II-forming pathways in the human heart. Circ Res 1997;80;219-27.

14 Mento PF, Wilkes BM. Plasma angiotensins and blood pressure during converting enzyme inhibition. Hypertension 1987; 9:III42-8

15 Nussberger J, Brunner DB, Waener B, et al.Specific measurement of angiotensin metabolites and in vitro generated angiotensin II in plasma. Hypertension 1986;8:

16 Capasso JM, Li P, Meggs LG, et al. Effecacy of angiotensinconverting enzyme inhibition and $\mathrm{A} 1$ receptor blockade on cardiac pump performance after myocardial infarction in cardiac pump performance after myocardial
rats. $\mathcal{F}$ Cardiovasc Pharmacol 1994;23:584-93.
17 Yoshiyama M, Kim S,Yamagishi H, et al. Cardioprotective effect of the angiotensin II type 1 receptor antagonist TCV-116 on ischemia reperfusion injury. Am Heart $\mathcal{f}$ 1994;128:1-6.

18 Di Pasquale P, Bucca V, Scalzo S, et al. Safety, tolerability, and neurohormonal changes of the combination captopril plus losartan in the early post-infarction period: a pilot study. Cardiovasc Drugs Ther 1998:12:211-16.

19 Schiller NB, Shah PM, Crawford $M$, et al. Recommendations for quantitation on left ventricle by two-dimensional echocardiography: American Society of Echocardiography committee on standards, subcommittee on quantitation of two-dimensional echocardiograms. F Am Soc Echocardiogr 1989;2:358-67.

20 Di Pasquale P, Paterna S, Valenza M, et al. Effects of captopril on myocardial protection during cardioplegia. Int $\mathcal{f}$ Cardiol 1993;42:225-30.

21 Skidgel RA, Erdos EC. The broad substrate specificity of human angiotensin I converting enzyme. Clinical and Experimental Hypertension 1987;A9:243-60.

22 Fogari R, Zoppi A, Tettamanti F, et al. Effects of nifedipine and indomethacin on cough induced by angiotensin converting enzyme inhibitors: a double blind randomized cross over study. F Cardiovasc Pharmacol 1992;19:670-3.

23 Aldigier JC, Uang $\mathrm{H}$, Dalmay $\mathrm{F}$, et al. Angiotensinconverting enzyme inhibition does not suppress plasma angiotensin II increase during exercise in humans. 7 Cardiovasc Pharmacol 1993:21:289-95.

24 Dickstein K, Chang P, Willenheimer R, et al. Comparison of the effects of losartan and enalapril on clinical status and exercise performance in patients with moderate or severe chronic heart failure. f Am Coll Cardiol 1995;26:438-45.

25 Yusuf S, Maggioni A, Held P, et al. Effects of candesartan, enalapril or their combination on exercise capacity, ventricular function, clinical deterioration and quality of life in heart failure: randomized evaluation of strategies of life in heart failure: randomized evaluation of strategies of lation 1997;96(suppl I):I-452.

26 Azizi M, Chatellier G, Guyene TT, et al. Additive effects of combined angiotensin on blood pressure and renin release in sodium deplete normotensives. Circulation 1995;92:82534.

27 Zhang X, Xie Y-W, Nasjletti A, et al. ACE-inhibitors promote nitric oxide accumulation to modulate myocardial oxygen consumption. Circulation 1997;95:176-82.

28 Di Pasquale P, Valdes L, Albano V, et al. Early captopril treatment reduces plasma endothelin concentrations in the acute and subacute phases of myocardial infarction: a pilot study. F Cardiovasc Pharmacol 1997;29:202-8.

29 Spinale GF, de Gasparro M, Whitebread S, et al. Modulation of the renin-angiotensin pathway through enzyme inhibition and specific receptor blockade in pacing-induced heart failure. I Effects on left ventricular pacrformance and neurohormonal systems. Circulation 1997;96:2365-96. 